The point by point response to the Grant Review Board and Reviewers' comments

Project No:
Project Title:

Principal Applicant (PA):

\section{8}

Safe City: a game-based educational approach to promote child safety knowledge and behaviours

Dr. Patrick IP

\title{
GRB Comments
}

\begin{tabular}{|l|l|}
\hline GRB(1): & The project is well written. \\
\hline$A:$ & Thank you very much for the comment. \\
\hline
\end{tabular}

\begin{tabular}{|c|c|}
\hline GRB(2): & $\begin{array}{l}\text { Elaborate the scientific evidence of the effectiveness of the proposed } \\
\text { intervention on the target group. }\end{array}$ \\
\hline A: & $\begin{array}{l}\text { Thank you for the suggestion. We have elaborated more in Section 13(b) (ii) and } \\
\text { (iii). } \\
\text { Digital games have been increasingly used for health promotion. A review of } 25 \\
\text { articles through December } 2006 \text { identified } 25 \text { video games which produced } \\
\text { positive changes in health-related behavior including diet, physical activity and } \\
\text { symptom management through various game elements such as immersive stories } \\
\text { and interactive game environment (1). As mentioned in our original proposal, to } \\
\text { our knowledge, there are only few digital safety games available on the market, } \\
\text { all of which are developed for western children and in English language. } \\
\text { Scientific evidence on the effectiveness of these safety games are scant as agreed } \\
\text { by Reviewer } 1 \text { and Reviewer } 2 \text {. In view of this research gap and the growing use } \\
\text { of digital games for education and training, this proposed project will develop a } \\
\text { 2D online city game with role-playing game (RPG) techniques, mini-games and } \\
\text { other game elements that foster interactions between players. Its effectiveness as } \\
\text { part of the safety education for Hong Kong Chinese young children will be } \\
\text { evaluated through a randomized controlled trial (RCT) study design. } \\
\text { Reviewer } 3 \text { pointed out that we did not give a thorough literature on training } \\
\text { games in our original proposal. This is because most of the existing safety } \\
\text { training studies were conducted through virtual reality games which allow } \\
\text { children to learn and practice safety techniques in realistic simulated situations. } \\
\text { A meta-analysis published in } 2014 \text { identified } 19 \text { articles on behavioral child } \\
\text { pedestrian safety interventions and found that repeated practice in vivo at street } \\
\text { side locations or in game-based virtual reality environments were the most } \\
\text { effective strategies (2). A RCT study compared the effectiveness of three } \\
\text { strategies of pedestrian safety training (street sidelfield, video/websites and } \\
\text { virtual reality (VR) training) in improving pedestrian safety skills among } 7 \text { - and } \\
\text { 8-year-old children (3). The study found that children trained in VR and field } \\
\text { environments had safer pedestrian behavior than control group children at post- } \\
\text { intervention and at follow-ups. } \\
\text { While VR techniques are increasingly used for education and training purposes }\end{array}$ \\
\hline
\end{tabular}


because of their advantages on risk, acceptance and effectiveness over previous street sidelfield training methods, game-based VR training requires expensive production and can be difficult for young children as they may have not yet learned the safe ways to navigate environments alone (4). To overcome these VR game limitations, another popular genre of video and computer games is roleplaying games (RPG) which gives the game developer more flexibility in designing developmentally appropriate adventure story with attractive characters and solvable challenges to engage the young participants. Like VR game, RPG allows players to strategize and interacts with objects and resources, but instead of training players in realistic simulated hazard situations, RPG players create their own avatar/character customized with unique attributes, skills and traits to play and advance in the cyber world. Furthermore, RPG can be combined with social game elements such as chat and items exchange to foster collaboration and communication among players (5). Some of these games are referred as massively multiplayer online role-playing game (MMORPG). RPGs or MMORPGs can facilitate learning by increasing student motivation and critical thinking and problem-solving skills $(6,7)$. Preliminary evidence showed that MMORPGs can lead to greater improvement in English communicative skills than traditional teaching method (8). In a recently published pilot RCT on HIV prevention, young adolescents participating in the smartphone game-based intervention with RPG techniques showed a larger gain in sexual health-related knowledge and self-efficacy compared with the control group (9). However, there is a lack of robust scientific evidence on RPG for injury prevention, highlighting the need to conduct this proposed project which will be able to demonstrate whether RPG can be used as a health promotion tool to prevent injury and potentially other health risk behaviors in Hong Kong.

References:

1. Baranowski, T., Buday, R., Thompson, D. I., \& Baranowski, J. (2008). Playing for real: video games and stories for health-related behavior change. American journal of preventive medicine, 34(1), 74-82.

2. Schwebel, D. C., Barton, B. K., Shen, J., Wells, H. L., Bogar, A., Heath, G., \& McCullough, D. (2014). Systematic review and meta-analysis of behavioral interventions to improve child pedestrian safety. Journal of pediatric psychology, 39(8), 826-845.

3. Schwebel, D. C., McClure, L. A., \& Severson, J. (2014). Teaching children to cross streets safely: A randomized, controlled trial. Health Psychology, 33(7), 628.

4. Smith, S., \& Ericson, E. (2009). Using immersive game-based virtual reality to teach fire-safety skills to children. Virtual reality, 13(2), 87-99.

5. Dickey, M. D. (2007). Game design and learning: A conjectural analysis of how massively multiple online role-playing games (MMORPGs) foster intrinsic motivation. Educational Technology Research and Development, 55(3), 253-273. 6. Umaschi Bers, M. (2001). Identity construction environments: Developing personal and moral values through the design of a virtual city. The Journal of the Learning Sciences, 10(4), 365-415.

7. Childress, M. D., \& Braswell, R. (2006). Using massively multiplayer online role-playing games for online learning. Distance Education, 27(2), 187-196.

8. Suh, S., Kim, S. W., \& Kim, N. J. (2010). Effectiveness of MMORPG-based instruction in elementary English education in Korea. Journal of computer 


\begin{tabular}{|l|l|}
\hline assisted learning, 26(5), 370-378. \\
9. Winskell, K., Sabben, G., Akelo, V., Ondeng'e, K., Obong'o, C., Stephenson, \\
R., ... \& Mudhune, V. (2018). A smartphone game-based intervention (Tumaini) \\
to prevent HIV among young Africans: pilot randomized controlled trial. JMIR \\
mHealth and uHealth, 6(8).
\end{tabular}

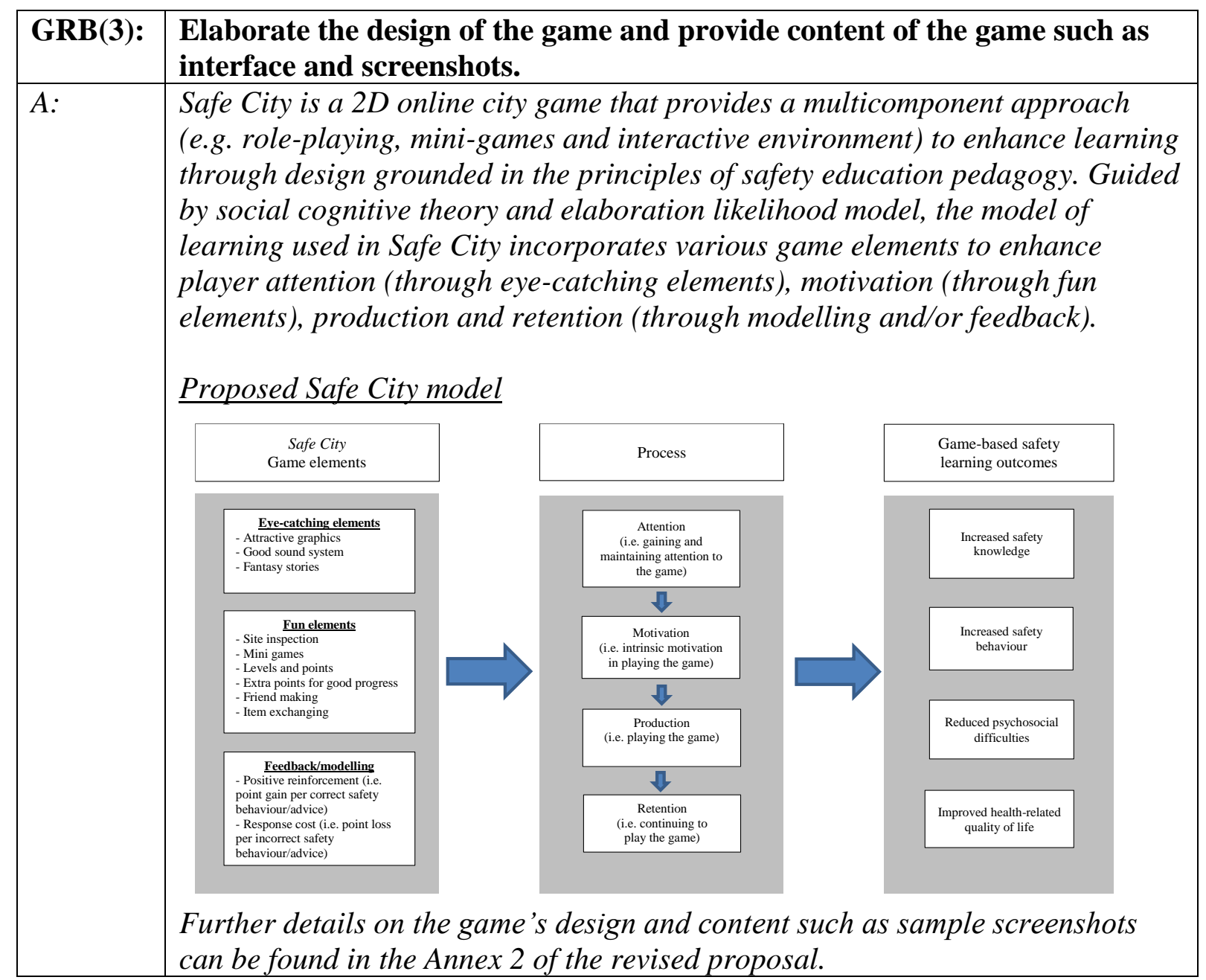

\begin{tabular}{|l|l|}
\hline GRB(4): & How to avoid the problem of contamination within schools? \\
\hline A: & $\begin{array}{l}\text { Thank you for pointing out the problem of potential contamination between } \\
\text { intervention and control group. Since the main intervention is delivered } \\
\text { through a web/app-based platform, we will provide unique login credentials } \\
\text { for students randomized into the intervention group. Such unique login } \\
\text { credentials will be required to access the game and participants would be } \\
\text { advised not to share and exchange such information with their peers. This } \\
\text { information has been added in the revised proposal (clean version, } \text { P.6). } \\
\text { Under this scheme, we are confident that contamination would be minimized. } \\
\text { To evaluate the degree of contamination, we will also ask in the questionnaire } \\
\text { whether the students in the control group accessed the game through other } \\
\text { peers' login credentials. Sensitivity per protocol analysis will be conducted } \\
\text { using this information. }\end{array}$ \\
\hline
\end{tabular}




\begin{tabular}{|l|l|}
\hline GRB(5): & Elaborate the sustainability of the proposed project. \\
\hline A: & $\begin{array}{l}\text { The Safe City game produced by this project shall be made available to the } \\
\text { public and local schools and shall continue to run under the management and } \\
\text { maintenance by the Department of Paediatrics and Adolescent Medicine of } \\
\text { the University of Hong Kong after the expiry of the funding support from the } \\
\text { Health Care and Promotion Scheme. } \\
\text { Upon completion of this project, flyers about the Safe City game will be made } \\
\text { and distributed in seminars and workshops as well as sent to all local } \\
\text { schools, news media, education groups and safety organizations to publicize } \\
\text { the game and increase its usage in the community. Information about the } \\
\text { game will also be posted in social networking websites (e.g. Facebook). Safe } \\
\text { City evaluation results will be shared in various meetings, conferences and } \\
\text { events to raise public awareness and usage of the game. This information has } \\
\text { been added in the revised proposal (clean version, P.11). } \\
\text { Meanwhile, we would continue to seek funding for upgrading the game to } \\
\text { serve other health education purposes and for use in multiple platforms. }\end{array}$ \\
\hline
\end{tabular}

\begin{tabular}{|l|l|}
\hline GRB(6): & An ethics approval from a recognized ethics committee is required \\
\hline A: & $\begin{array}{l}\text { We are in process of applying for the ethics approval. The scanned copy of the } \\
\text { ethics approval will be submitted to the GRB by email as specified in the } \\
\text { decision letter. }\end{array}$ \\
\hline
\end{tabular}

\begin{tabular}{|l|l|}
\hline GRB(7): & $\begin{array}{l}\text { Clarify if the following budget item: "Incentives for participants" (\$9,200) } \\
\text { should be re-named as "Award for participants". }\end{array}$ \\
\hline$A:$ & $\begin{array}{l}\text { Thank you very much for your suggestion. The following item "Incentives for } \\
\text { participants" have been re-named as "Award for participants". }\end{array}$ \\
\hline
\end{tabular}

\begin{tabular}{|c|c|}
\hline GRB(8): & $\begin{array}{l}\text { Provide justification and breakdown for the following budget item: "Game } \\
\text { design and development" }(\$ 780,000) \text {. }\end{array}$ \\
\hline A: & $\begin{array}{l}\text { Thank you very much for your comments. Justification and breakdown of the } \\
\text { budget item "Game design and development" has been added, as below: } \\
\text { Game programming: } \$ 270,000 \\
\text { A game programmer will be hired for } 12 \text { months to develop codebase for the } \\
\text { proposed game. } \\
\text { Gaming component designing: } \$ 280,000 \\
\text { A game designer will be hired for } 12 \text { months to design the game content } \\
\text { including creating goals, rules, challenges, game point allocation, level system } \\
\text { that could produce a desirable gaming environment for the users to interact and } \\
\text { engage in the game. } \\
\text { Graphics or Art design: } \$ 200,000 \\
\text { A game artist will be hired for } 10 \text { months to create } 2 D \text { art for the visual } \\
\text { elements of a video game, such as characters, vehicles, props, scenery, } \\
\text { background, objects, colors, textures, and clothing. } \\
\text { Game sound design: } \$ 30,000 \\
\text { A sound designer will be hired at the final stage of the game design to generate } \\
\text { and adjust audio elements for the game. }\end{array}$ \\
\hline
\end{tabular}




\section{Reviewer 1}

\begin{tabular}{|l|l|}
\hline R1(1): & $\begin{array}{l}\text { Promoting children's safety knowledge and behaviors via a game-based } \\
\text { approach is novel. The proposed work is highly relevant to the thematic } \\
\text { priority "Injury prevention". }\end{array}$ \\
\hline$A:$ & Thank you very much for your comments. \\
\hline
\end{tabular}

\begin{tabular}{|l|l|}
\hline R1(2): & $\begin{array}{l}\text { The aims and objectives are clearly defined. They are well informed by } \\
\text { scientific evidence. }\end{array}$ \\
& $\begin{array}{l}\text { As the applicants mentioned, there are quite limited number of digital safety } \\
\text { games on the market. But it is useful to provide more evidence support for } \\
\text { using the digital games for enhancing health-related knowledge and behaviors } \\
\text { (other than safety). }\end{array}$ \\
\hline$A:$ & $\begin{array}{l}\text { Thank you very much for your comments. We have elaborated the scientific } \\
\text { evidence on digital games in section (b) (ii) and (iii). }\end{array}$ \\
\hline
\end{tabular}

\begin{tabular}{|l|l|}
\hline R1(3a): & $\begin{array}{l}\text { The implementation plan is detailed and appropriate for the project. } \\
\text { Sample size has been adequately justified. } \\
\text { The proposed timeline is feasible. }\end{array}$ \\
\hline$A:$ & Thanks for your comments. \\
\hline
\end{tabular}

\begin{tabular}{|l|l|}
\hline $\mathbf{R 1}(\mathbf{3 b}):$ & $\begin{array}{l}\text { The only concern is the potential problem of contamination. The same } \\
\text { school has students in both intervention and control group. How to ensure } \\
\text { that contamination won't happen? }\end{array}$ \\
\hline A: & $\begin{array}{l}\text { Thank you for pointing out the problem of potential contamination between } \\
\text { intervention and control group. Since the main intervention is delivered through } \\
\text { a web/app-based platform, we will provide unique login credentials for students } \\
\text { randomized into the intervention group. Such unique login credentials will be } \\
\text { required to access the game and participants would be advised not to shared } \\
\text { and exchange such information with their peers. This information has been } \\
\text { added in the revised proposal (clean version, P.6). Under this scheme, we are } \\
\text { confident that contaminations would be minimized. To evaluate the degree of } \\
\text { contamination, we will also ask in the questionnaire whether the students in the } \\
\text { control group accessed the game through other peers' login credentials. } \\
\text { Sensitivity per protocol analysis will be conducted using this information. }\end{array}$ \\
\hline
\end{tabular}

\begin{tabular}{|l|l|}
\hline R1(4): & $\begin{array}{l}\text { The indicators are clearly defined and outcome evaluation tools are } \\
\text { appropriate for the purposes }\end{array}$ \\
\hline$A:$ & Thanks for your comments \\
\hline
\end{tabular}

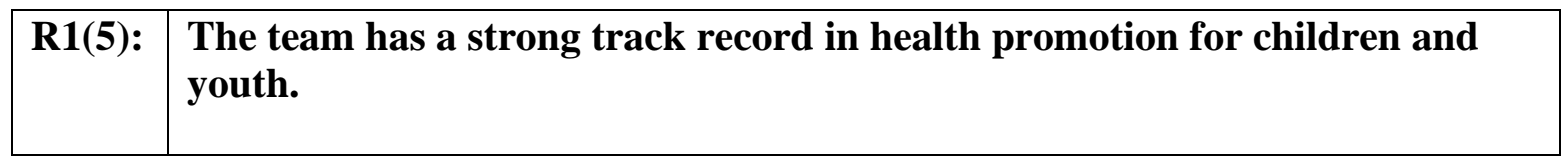




\begin{tabular}{|l|l|}
\hline & $\begin{array}{l}\text { The team consists of cross-sector collaborations among academic } \\
\text { institutions and NGO. }\end{array}$ \\
\hline$A:$ & Thanks for your comments. \\
\hline
\end{tabular}

\begin{tabular}{|l|l|}
\hline R1(6): & $\begin{array}{l}\text { It was mentioned that the preliminary design for the game has already been } \\
\text { completed at the time of the application. Need to clarify whether the budget } \\
\text { requested is to cover the remaining work. }\end{array}$ \\
\hline$A:$ & $\begin{array}{l}\text { Thanks for your comments. The preliminary design of the game, including the } \\
\text { main goals, mode of gaming, and target audience of the game, was developed by } \\
\text { the project team during the application process. However, a professional game } \\
\text { development team with expertise in different areas of game development } \\
\text { including game programming, game design, graphics designs, and audio design } \\
\text { is needed and essential for producing an attractive, playable and immersive } \\
\text { game. }\end{array}$ \\
\hline
\end{tabular}

\begin{tabular}{|l|l|}
\hline R1(7): & $\begin{array}{l}\text { The developed digital game could be used after the completion of this } \\
\text { project. } \\
\text { It is not clear how local resources are mobilized to continue usage of the } \\
\text { developed game in the community. }\end{array}$ \\
\hline$A:$ & $\begin{array}{l}\text { Thank you for the comment. The Safe City game produced by this project shall } \\
\text { be made available to the public and local schools and shall continue to run } \\
\text { under the management and maintenance by the Department of Paediatrics and } \\
\text { Adolescent Medicine of the University of Hong Kong after the expiry of the } \\
\text { funding support from the Health Care and Promotion Scheme. }\end{array}$ \\
$\begin{array}{l}\text { Upon completion of this project, flyers about the Safe City game will be made } \\
\text { and distributed in seminars and workshops as well as sent to all local schools, } \\
\text { news media, education groups and safety organizations to publicize the game } \\
\text { and increase its usage in the community. Information about the game will also } \\
\text { be posted in social networking websites (e.g. Facebook). Safe City evaluation } \\
\text { results will be shared in various meetings, conferences and events to raise } \\
\text { public awareness and usage of the game. This information has been added in } \\
\text { the revised proposal (clean version, P.11). } \\
\text { Meanwhile, we would continue to seek funding for upgrading the game to serve } \\
\text { other health education purposes and for use in multiple platforms. }\end{array}$
\end{tabular}

\begin{tabular}{|l|l|}
\hline R1(8a): & Strengths: A well written proposal and a strong team \\
\hline$A:$ & Thank you very much for your comments. \\
\hline
\end{tabular}

\begin{tabular}{|l|l|}
\hline $\mathbf{R 1}(\mathbf{8 b}):$ & Weaknesses: clarify how contamination could be avoided. \\
\hline A: & $\begin{array}{l}\text { As described above, we will minimize contamination through unique login } \\
\text { credentials for each student in the intervention group and will evaluate the } \\
\text { effect of continuation in sensitivity per protocol analysis. }\end{array}$ \\
\hline
\end{tabular}




\begin{tabular}{|c|c|}
\hline R1(8c): & Weaknesses: Strengthen the sustainability plan. \\
\hline A: & $\begin{array}{l}\text { The sustainability plan has been strengthened by adding "Upon completion of } \\
\text { this project, flyers about the Safe City game will be made and distributed in } \\
\text { seminars and workshops as well as sent to all local schools, news media, } \\
\text { education groups and safety organizations to publicize the game and increase } \\
\text { its usage in the community. Information about the game will also be posted in } \\
\text { social networking websites (e.g. Facebook). Safe City evaluation results will be } \\
\text { shared in various meetings, conferences and events to raise public awareness } \\
\text { and usage of the game" in the revised proposal (clean version, } P .11) \text {. }\end{array}$ \\
\hline
\end{tabular}


$\underline{\text { Reviewer } 2}$

\begin{tabular}{|l|l|}
\hline R2(1): & $\begin{array}{l}\text { The project is innovative in using a digital game based experiential learning } \\
\text { approach to promote child safety knowledge and behaviors, addressing } \\
\text { injury prevention thematic priority needs among children in HK, rather } \\
\text { than the traditional safety programs in formal education settings lacking } \\
\text { practice and interactive elements to enhance student learning motivation } \\
\text { and behavioral changes. }\end{array}$ \\
\hline$A:$ & Thank you very much for your comments. \\
\hline
\end{tabular}

\begin{tabular}{|l|l|}
\hline R2(2): & $\begin{array}{l}\text { Aim and objectives were well articulated. The proposed strategy was well } \\
\text { supported by related scientific evidence. }\end{array}$ \\
\hline$A:$ & Thank you very much for your comments. \\
\hline
\end{tabular}

\begin{tabular}{|l|l|}
\hline R2(3): & $\begin{array}{l}\text { The target group is over 1,000 P4-6 children. The implementation plan and } \\
\text { milestones are well designed including the content of the city game in } \\
\text { achieving its stated objectives. }\end{array}$ \\
\hline A: & Thank you very much for your comments. \\
\hline
\end{tabular}

\begin{tabular}{|l|l|}
\hline R2(4): & $\begin{array}{l}\text { RCT evaluation plan well designed with control group and well selected } \\
\text { indicators, evaluating the } 5 \text { specific objectives of the project, comparing the } \\
\text { effectiveness of the project approach with traditional strategy in changing } \\
\text { children's safety knowledge and behaviours, enhancing their health-related } \\
\text { quality, and reducing their psychosocial difficulties }\end{array}$ \\
\hline$A:$ & Thank you very much for your comments. \\
\hline
\end{tabular}

\begin{tabular}{|l|l|}
\hline R2(5): & Strong and experienced team from multi-disciplinary background. \\
\hline$A:$ & Thanks for your comments \\
\hline
\end{tabular}

\begin{tabular}{|l|l|}
\hline R2(6): & $\begin{array}{l}\text { Mainly on RA and design \& development of the game. } \\
\text { Justified and reasonable. }\end{array}$ \\
\hline$A:$ & Thanks for your comments \\
\hline
\end{tabular}

\begin{tabular}{|l|l|}
\hline R2(7): & $\begin{array}{l}\text { The game platform could be readily extended to new children users and } \\
\text { upgraded in content and design to meet the new safety education needs of } \\
\text { the children in our city context. }\end{array}$ \\
\hline$A:$ & Thanks for your comments \\
\hline
\end{tabular}

\begin{tabular}{|l|l|}
\hline R2(8): & $\begin{array}{l}\text { Strengths: } \\
\text { 1. Innovative in approach. }\end{array}$ \\
& $\begin{array}{l}\text { 2. Addressing limitations of traditional approach } \\
\text { 3. Well planned in implementation and evaluation }\end{array}$ \\
\hline 4. Strong and experienced team
\end{tabular}




\begin{tabular}{|l|l|}
\hline R2(9a): & $\begin{array}{l}\text { Weaknesses: } \\
\text { 1. The game appears not interactive among children learners, thus } \\
\text { reducing the peer learning effects }\end{array}$ \\
\hline$A:$ & $\begin{array}{l}\text { Thank you for your comments. To foster peer learning, we would add in social } \\
\text { game features. For example, players can make friends with other players and } \\
\text { exchange items and ideas with each other within the game environment, such } \\
\text { that players can work together to solve the problems in the cyber city. This } \\
\text { additional game feature has been added in the revised proposal (clean version, } \\
\text { P.16). }\end{array}$ \\
\hline
\end{tabular}

\begin{tabular}{|l|l|}
\hline R2(9a): & $\begin{array}{l}\text { Weaknesses: } \\
\text { 2. How could it be integrated into the traditional classroom learning } \\
\text { approach? }\end{array}$ \\
\hline A: & $\begin{array}{l}\text { E-learning is important for high quality education and training. Safe City as an } \\
\text { e-learning resource can promote self- and peer-learning, which in turn could } \\
\text { increase and improve student-teacher interactions, as traditional classroom } \\
\text { learning focuses on teacher-led activities which may not foster students' } \\
\text { critical thinking problem solving and decision making skills, whereas Safe City } \\
\text { can let children learn and explore the materials at their own pace. After } \\
\text { gameplay, teachers can do in-class discussion on students' gameplay and } \\
\text { learning experience (e.g. what kind of knowledge students learned from the } \\
\text { game and which safety domains students would like to know more etc) that } \\
\text { would be useful for teachers'preparation of subsequent teaching materials. } \\
\text { Teachers can also use the Safe City game to make healthy competition between } \\
\text { students to make learning more interesting. Furthermore, students can access } \\
\text { Safe City an unlimited number of times which could consolidate the materials } \\
\text { learned in class. This information has been added in the revised proposal } \\
\text { (clean version, P.2). }\end{array}$ \\
\hline
\end{tabular}


Reviewer 3

\begin{tabular}{|c|c|}
\hline R3(1a): & $\begin{array}{l}\text { The investigators argued that traditional health education approaches are } \\
\text { usually classroom-based and use one-way method to deliver the } \\
\text { information from the instructor to the audience, however, this is too } \\
\text { subjective and lack of literature support. School-based and parent oriented } \\
\text { approaches are still the most effective way for children in learning. I don't } \\
\text { pretty agree with the team and will still believe that the best way to learn } \\
\text { safety is to have it be integrated to the school system and in the family. } \\
\text { There does not exist any conflicts with parent-child collaborative decision } \\
\text { making as cited in (iii) }\end{array}$ \\
\hline A: & 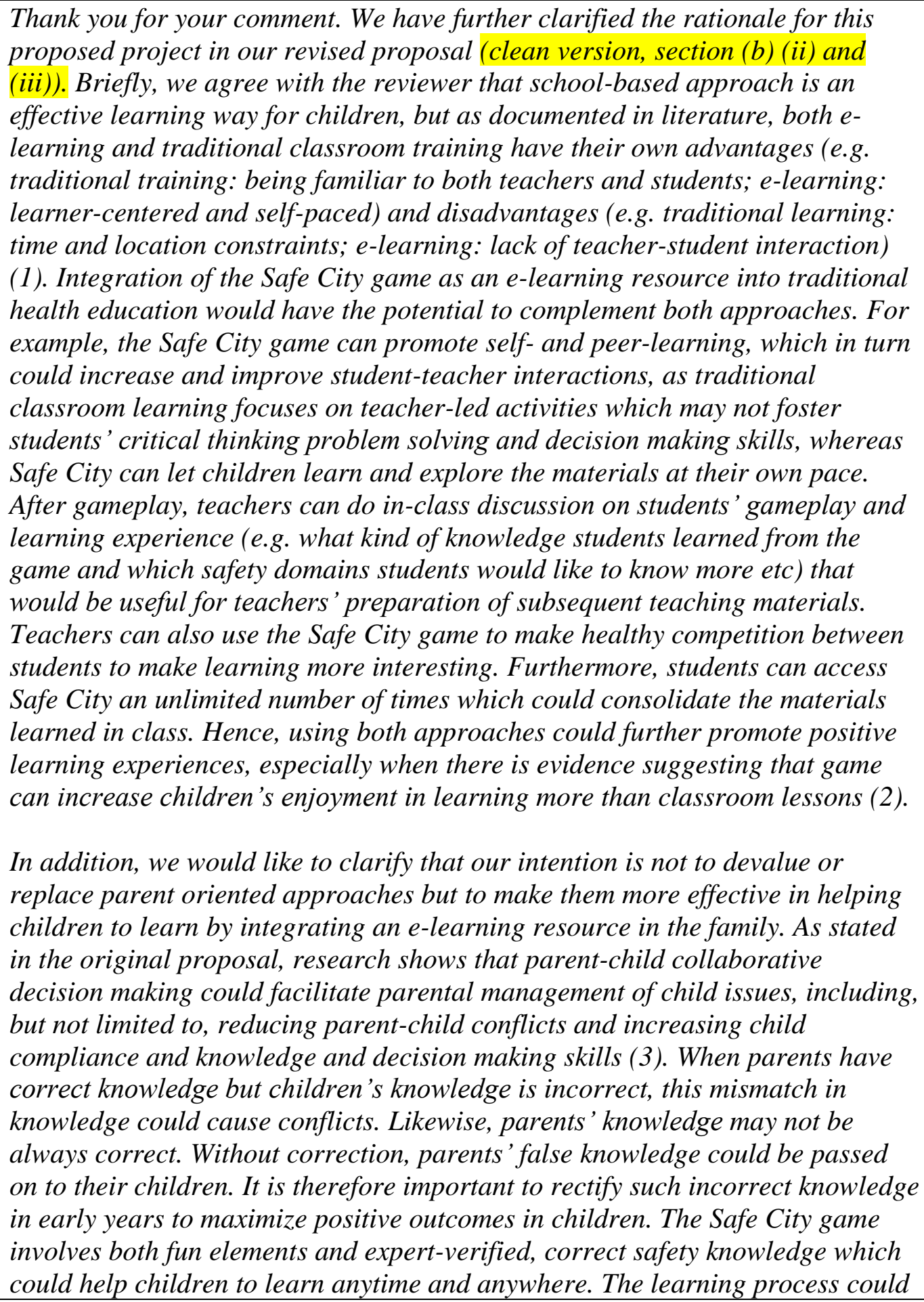 \\
\hline
\end{tabular}




\begin{tabular}{|l|l|}
\hline $\begin{array}{l}\text { also involve parents, such as involving both parents and children to play the } \\
\text { game together. }\end{array}$ \\
References: \\
1. Zhang, D., Zhao, J. L., Zhou, L., \& Nunamaker Jr, J. F. (2004). Can e- \\
learning replace classroom learning?. Communications of the ACM, \\
47(5), 75-79. \\
2. Furió, D., Juan, M. C., Segui, I., \& Vivó, R. (2015). Mobile learning vs. \\
traditional classroom lessons: a comparative study. Journal of \\
Computer Assisted Learning, 31(3), 189-201. \\
3. Miller VA. Parent-Child Collaborative Decision Making for the \\
Management of Chronic Illness: A Qualitative Analysis. Families, \\
systems \& health: the journal of collaborative family healthcare. \\
2009;27(3):249-66.
\end{tabular}

\begin{tabular}{|c|c|}
\hline R3(1b): & $\begin{array}{l}\text { The team highlighted the prevalence of childhood injuries in their recent } \\
\text { HCPF-funded project (Ref no.: } 26120254 \text { ) but the paper has not been } \\
\text { published yet. }\end{array}$ \\
\hline A: & $\begin{array}{l}\text { Thanks for your comments. We would like to clarify that two papers have been } \\
\text { published using the data collected in the HCPF-funded project (Ref no.: } \\
26120254) \text { to examine the prevalence of fall-related injuries among children } \\
\text { and adolescent in Hong Kong, and to study the association with stock market } \\
\text { fluctuation and rate of self-harm among adolescent in Hong Kong. Both studies } \\
\text { have been published in peer-reviewed journals: } \\
\text { Lee, J. C. Y., Tung, K. T. S., Li, T. M., Ho, F. K. W., Ip, P., Wong, W. H. S., \& } \\
\text { Chow, C. B. (2017). Fall-related attendance and associated hospitalisation of } \\
\text { children and adolescents in Hong Kong: a 12-year retrospective study. BMJ } \\
\text { open, } 7(2), \text { e013724. } \\
\text { Wong, W. H. S., Lee, J. C. Y., Ho, F. K. W., Li, T. M. H., Ip, P., \& Chow, C. B. } \\
\text { (2017). Stock market fluctuations and self-harm among children and } \\
\text { adolescents in Hong Kong. International journal of environmental research and } \\
\text { public health, 14(6), 623. }\end{array}$ \\
\hline
\end{tabular}

\begin{tabular}{|l|l|}
\hline R3(1c): & $\begin{array}{l}\text { Although the investigators adopt the experiential gaming model proposed } \\
\text { by Kiili (2005) into their own game model in Annex 1, but there is no } \\
\text { description on the figure in the proposal and how it is distinct from the old } \\
\text { model. }\end{array}$ \\
\hline$A:$ & $\begin{array}{l}\text { Thank you for your comment. } \\
\text { The experiential gaming model proposed by Kiili (2005) emphasizes the } \\
\text { importance of positive user experiences and makes use of immediate feedback, } \\
\text { clear goals and developmentally appropriate challenges to maximize the impact } \\
\text { of educational games (1). The central tenet of this model is to construct a } \\
\text { knowledge base for a specific subject/topic through practice in the game world. } \\
\text { By adopting this model, the Safe City game also uses positive user experiences } \\
\text { and immediate feedback to change the player's knowledge as illustrated in }\end{array}$ \\
\hline
\end{tabular}




\begin{tabular}{|l}
\hline $\begin{array}{l}\text { Annex 1. The difference is that Kiili's model is a general gaming model but our } \\
\text { model is specific to safety game. Briefly, the player's journey would begin with } \\
\text { identifying the hazard situations based on prior knowledge and cues provided } \\
\text { by the game (challenges). Then, the player would pick a solution to removing } \\
\text { the hazard (active experimentation). The game system would then tell the player } \\
\text { whether his/her solution choice is correct or not (reflective observation). Based } \\
\text { on the game feedback, the player would be able to update or confirm the } \\
\text { existing base of safety knowledge (schemata construction) which could be used } \\
\text { to guide future relevant decision making or behavior. These details have been } \\
\text { added in the revised proposal (clean version, P.2). }\end{array}$ \\
$\begin{array}{l}\text { Reference: } \\
\text { 1. Kiili K. Digital game-based learning: Towards an experiential gaming model. } \\
\text { The Internet and Higher Education. 2005;8(1):13-24. }\end{array}$
\end{tabular}

\begin{tabular}{|c|c|}
\hline R3(2): & $\begin{array}{l}\text { The aims of the proposal are appropriate. } \\
\text { The game design as written in Annex } 2 \text {, however, is only a game flow } \\
\text { similar to those written down by a software game designer. In the } \\
\text { background section, the literature about similar game design is lacking. } \\
\text { The investigators should write the rationale behind the game from a more } \\
\text { philosophical way: } \\
\text { 1. Are they using the concept of "Response-cost" by giving them some } \\
\text { tokens at the beginning and deduct whenever the child breaks the } \\
\text { rule? What is its advantage? } \\
\text { 2. Are they using "Positive reinforcement" whenever the child obeys } \\
\text { the safety rule? What is its advantage? } \\
\text { 3. What is the "immerse" level of virtual reality of the game? What is } \\
\text { its advantage? } \\
\text { 4. If the designers want to emphasis on following the "stop, look, listen, } \\
\text { think" rule, this should be highlighted in the proposal as the main } \\
\text { element as it is a cognitive-behavioral therapy (CBT) approach and } \\
\text { help the child to make correct decision explicitly through implicitly } \\
\text { learning. Apart from this, I also suggest adding "go" and "check" } \\
\text { after "think". } \\
\text { 5. Any cueing level? In order to remind the child to achieve the goal in } \\
\text { a positive way? } \\
\text { 6. What is the scoring of the game? Any rules for scoring, like correct } \\
\text { and incorrect responses, perseveration responses, cues level, reaction } \\
\text { time, total time of fame, total points of game, etc. } \\
\text { 7. Any other augmented feedbacks and interactive components? Visual } \\
\text { and auditory inputs? Other features like motor which involve actual } \\
\text { moving the checkers, etc. } \\
\text { This reflects that the research team does not include experts in task-specific } \\
\text { training game design }\end{array}$ \\
\hline A: & Thank you for the questions. Below please find our response to each question: \\
\hline
\end{tabular}




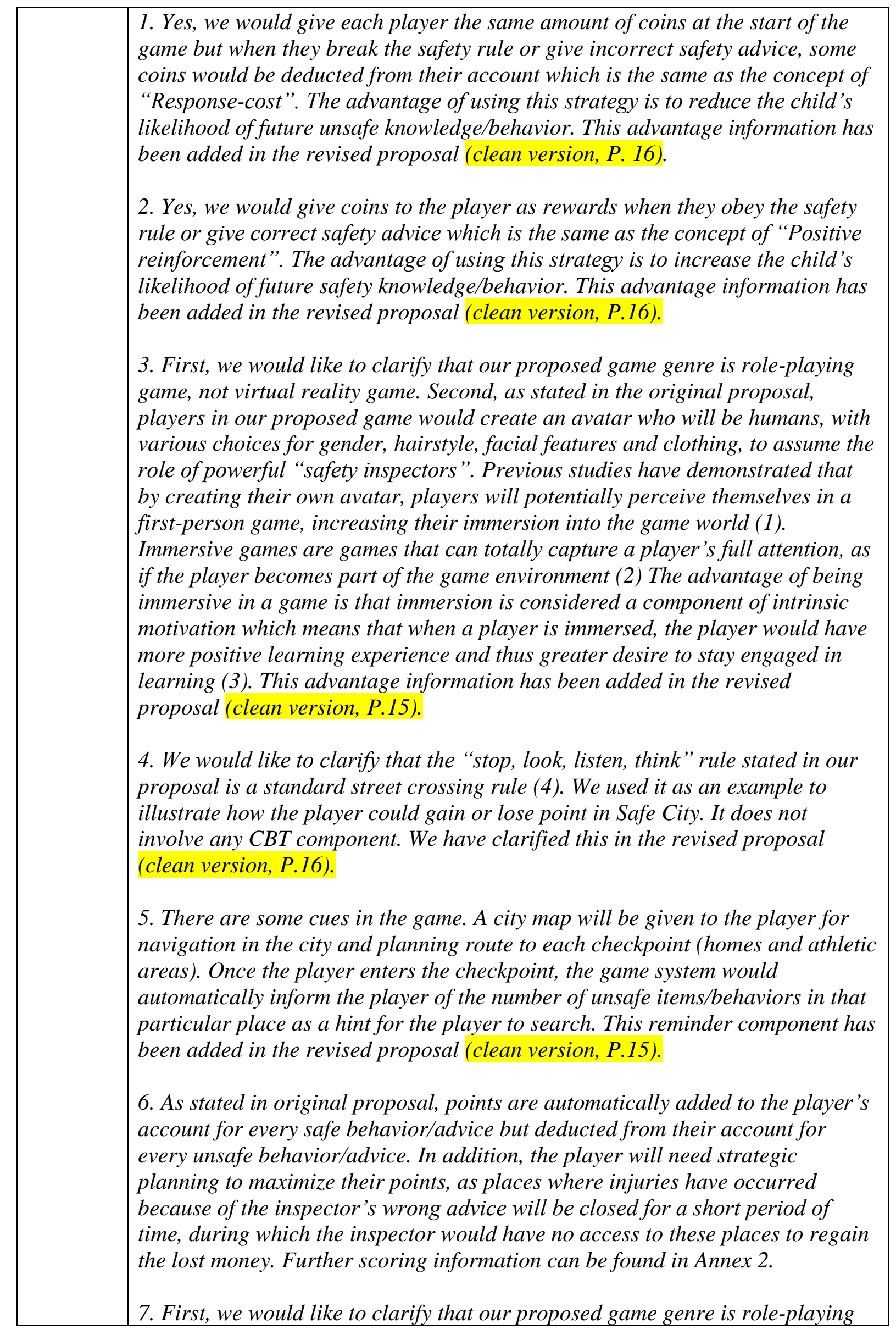




\begin{tabular}{|l|l|}
\hline game, not virtual reality game. Feedback would be given to the player in the \\
form of adding or deducting game points which indicates whether the player \\
made a correct or incorrect choiceladvice. In addition to the player-item \\
interactions, we would also add in elements to foster interactions between \\
players. For example, players can make friends with other players and \\
exchange items and ideas with each other within the game environment, such \\
that players can work together to solve the problems in the cyber city. This \\
additional social game feature has been added in the revised proposal (clean \\
version, P.16). As for the visual and auditory inputs and other motor features, \\
their quantity and quality would largely depend on the funding amount and \\
hence we would discuss later with the professional game development team \\
after the project is officially launched. \\
References: \\
1. You, S., Kim, E., \& Lee, D. (2017). Virtually real: exploring avatar \\
identification in game addiction among massively multiplayer online role- \\
playing games (MMORPG) players. Games and Culture, 12(1), 56-71. \\
2. Baranowski, T., Buday, R., Thompson, D. I., \& Baranowski, J. (2008). \\
Playing for real: video games and stories for health-related behavior change. \\
American journal of preventive medicine, 34(1), 74-82. \\
3. Paras, B. (2005). Game, motivation, and effective learning: An integrated \\
model for educational game design. \\
4. Zeedyk, M. S., Wallace, L., \& Spry, L. (2002). Stop, look, listen, and think?: \\
What young children really do when crossing the road. Accident Analysis \& \\
Prevention, 34(1), 43-50.
\end{tabular}

\begin{tabular}{|l|l|}
\hline $\mathbf{R 3}(3):$ & The target group is appropriate. \\
\hline$A:$ & Thanks for your comments \\
\hline
\end{tabular}

\begin{tabular}{|l|l|}
\hline R3(4): & $\begin{array}{l}\text { In such a similar training game design study, outcomes can be divided into } \\
\text { 2 types: task-specific and domain-specific outcomes. The team identifies } \\
\text { task-specific game outcomes as primary outcomes, and domain knowledge } \\
\text { such as safety knowledge and clients' self-perceived reflections such as } \\
\text { HRQOL and psychosocial difficulties as secondary outcomes. }\end{array}$ \\
$\begin{array}{l}\text { The secondary outcomes are appropriate but the investigators fail to make } \\
\text { sure of the task-specific outcomes. }\end{array}$ \\
$\begin{array}{l}\text { The task-specific outcomes should be the data obtained from the game } \\
\text { which provides big data from more than one thousand cases and the } \\
\text { difference in responses and the interactions in different safety domains } \\
\text { such as unsafe knowledge, unsafe behaviours, unsafe environments, unsafe } \\
\text { management, etc. Other parameters such as correct and incorrect } \\
\text { responses, preservation responses, cues level, reaction time, total time of } \\
\text { game, total points of game, etc. have not been mentioned in the evaluation. } \\
\text { The outcome can also be either reducing the likelihood and consequence of } \\
\text { accidents, or both. }\end{array}$ \\
\hline
\end{tabular}




\begin{tabular}{|c|c|}
\hline$A:$ & $\begin{array}{l}\text { Thank you very much for the suggestions. First, we would like to clarify that the } \\
\text { proposed online city game is } 2 D \text { with role-playing and interactive elements to } \\
\text { reinforce correct safety knowledge in students based on experiential learning } \\
\text { theory, instead of training students to practice safety techniques in a simulated } \\
\text { environment. To test whether Safe City can achieve this goal, a user log system } \\
\text { will be developed to record all in-app activity. Because all player activities will } \\
\text { be time-stamped, the time spent on overall and specific parts of the game can be } \\
\text { calculated. Total time of game and total points of game have been included in } \\
\text { the original proposal under the "Game usage statistics" section. Further, in } \\
\text { response to the reviewer's comments, we have revised the proposal to include } \\
\text { more task-specific outcomes, including the number of correct and incorrect } \\
\text { responses in each safety domain and the number of attempts needed to reach the } \\
\text { correct answer (clean version, P. 9) which could help us and other relevant } \\
\text { authorities and agencies to identify area(s) within the safety education } \\
\text { curriculum that require improvement. } \\
\text { For other suggested parameters such as cues level and reaction time, although } \\
\text { they are good indicators of executive functions (e.g. attentional control and } \\
\text { cognitive flexibility), these data are more feasible to collect in virtual reality } \\
\text { games. In future, if we could secure extra funding to support further } \\
\text { development of this game, we would consider upgrading it to a more advanced } \\
\text { game such as virtual reality game that would be more able to do both health } \\
\text { education and behavioral training for children. }\end{array}$ \\
\hline
\end{tabular}

\begin{tabular}{|c|c|}
\hline R3(5): & $\begin{array}{l}\text { The research team consists of experts in various fields including injury, } \\
\text { child health, etc. but not in game design. } \\
\text { The team does not have previous published papers in this area. }\end{array}$ \\
\hline A: & $\begin{array}{l}\text { We understand the reviewer's concern in our game design expertise, but we } \\
\text { would like to highlight our experience in game design for health promotion. } \\
\text { First, Professor TC Pong is a senior professor in computer science with } \\
\text { extensive research and practice experiences in multimedia computing and e- } \\
\text { learning, including gamification of education/health promotion. Second, Dr. } \\
\text { Patrick Ip and Dr. CB Chow were the principal investigators of previous } \\
\text { HMRF-funded projects on using quiz, game competition to reduce smoking and } \\
\text { alcohol drinking behaviors. Both studies have been published as indicated } \\
\text { below: } \\
\text { Ip P, Lam TH, Chan SSC, Ho FK, ..., Chow CB. Use of Internet Viral Marketing } \\
\text { to Promote Smoke-Free Lifestyles among Chinese Adolescents. PLoS ONE. } \\
2014 ; 9(6): \text { e99082. } \\
\text { Ip P, Chan KL, Chow CB, Lam TH, Ho SY, Wong WH, Wong MF. An internet- } \\
\text { based intervention to promote alcohol-related attitudinal and behavioral change } \\
\text { among adolescents: protocol of a cluster randomized controlled trial. JMIR } \\
\text { research protocols. } 2016 \text { Apr;5(2). }\end{array}$ \\
\hline
\end{tabular}




\begin{tabular}{|l|l|}
\hline $\mathbf{R 3}(6):$ & $\begin{array}{l}\text { The game development fee } \mathbf{\$ 7 8 0 , 0 0 0} \text { is very expensive. There is no } \\
\text { justification about the expenditure as well as item breakdown on this } \\
\text { amount in the budget }\end{array}$ \\
\hline$A:$ & $\begin{array}{l}\text { Thank you very much for your comments. Justification and breakdown of the } \\
\text { budget item "Game design and development" has been added, as below: } \\
\text { Game programming: } \mathbf{\$ 2 7 0 , 0 0 0} \\
\text { A game programmer will be hired for } 12 \text { months to develop codebase for the } \\
\text { proposed game. } \\
\text { Gaming component designing: } \mathbf{\$ 2 8 0 , 0 0 0} \\
\text { A game designer will be hired for } 12 \text { months to design the game content } \\
\text { including creating goals, rules, challenges, game point allocation, level system } \\
\text { that could produce a desirable gaming environment for the users to interact and } \\
\text { engage in the game. } \\
\text { Graphics or Art design: } \mathbf{\$ 2 0 0 , 0 0 0} \\
\text { A game artist will be hired for } 10 \text { months to create } 2 D \text { art for the visual } \\
\text { elements of a video game, such as characters, vehicles, props, scenery, } \\
\text { background, objects, colors, textures, and clothing. } \\
\text { Game sound design: } \$ \mathbf{3 0 , 0 0 0} \\
\text { A sound designer will be hired at the final stage of the game design to generate } \\
\text { and adjust audio elements for the game. }\end{array}$ \\
\hline
\end{tabular}

\begin{tabular}{|c|c|}
\hline R3(7): & $\begin{array}{l}\text { The field of childhood injury is an important area but does not receive lots } \\
\text { of attention. Promoting safety to reduce accidents in children population is } \\
\text { an important and new branch on health promotion. } \\
\text { The idea of game in health promotion in childhood safety is innovative and } \\
\text { child-friendly as children like to play smartphone nowadays. } \\
\text { The use of RCT to carry out the experimental intervention (game) by } \\
\text { comparing with control group using paper and electronic educational } \\
\text { materials is appropriate. However, the proposal does not include a } \\
\text { thorough literature on training games, the methodology fails to describe the } \\
\text { philosophical design of the game and the domains of childhood safety, and } \\
\text { the team is not experienced in designing training games. }\end{array}$ \\
\hline A: & $\begin{array}{l}\text { Thank you for your comments. We have substantially revised the Background } \\
\text { and Methodology sections to provide more details to support our proposal. We } \\
\text { would also like to clarify that our proposed game is } 2 D \text { with role-playing game } \\
\text { techniques, mini-games and other game elements that foster interactions } \\
\text { between players. We are not designing a behavioral virtual reality training } \\
\text { game, as such game requires much more time and resources to produce but we } \\
\text { would consider this possibility in future development phase. And as clarified } \\
\text { earlier, our team has experiences in developing game-based health intervention. }\end{array}$ \\
\hline
\end{tabular}

R3(8a): $\quad$ Strengths:

1. Childhood safety is a good area of study in health promotion

2. The team has a good track record in childhood injury studies

3. Using game is an innovative idea. 


\begin{tabular}{|l|l|}
\hline $\mathbf{R 3}(\mathbf{8 b}):$ & $\begin{array}{l}\text { Weaknesses: } \\
\text { 1. The proposal does not include a thorough literature on training } \\
\text { games. }\end{array}$ \\
2. The methodology fails to describe the philosophical design of the \\
game and the domains of childhood safety. \\
3. The team is not experienced in designing games. \\
4. The task-specific outcome measure is poorly described and utilized \\
which reflected that the team does not have experiences in using \\
training games.
\end{tabular}

